\title{
Examining Methods Implementers Use in Delivering the HIVIAIDS Programmes in Universities
}

\author{
Doctor Denias Muzenda (PhD, MEDCA,MEAPPS,BED,CE)
}

PhD University of Fort Hare, MEDCA-University of Zimbabwe, MEDAPPS-ZOU, BED-University of Zimbabwe, CE-University of Zimbabwe

Email: muzendad@justice.com

\section{Symphorosa Rembe}

School of Further and Continuing Education University Of Fort Hare, South Africa

\section{Doi:10.5901/mjss.2014.v5n23p1124}

\begin{abstract}
HIV and AIDS programme implementers or facilitators and lecturers are mandated to use a variety of methods as a means of teaching and distributing HIV and AIDS related information or material to students. The study made use of the Post-positivist paradigm. Thirty- nine lecturers, 24 students, 3 senior health workers and 3 NGO officials made up the sample. Data was collected through questionnaires, face to face interviews, focus group discussions, document analysis, and observations. SPSS computer software was used to analyse quantitative data and qualitative data was grouped into themes. This study revealed that time allocated for HIV and AIDS lessons in the curriculum was not adequate. University lecturers used lecture method, group discussion, assessment methods as key methods of implementing the programme. The study revealed that HIV and AIDS programmes were not well managed or coordinated though they were taught throughout the year in all universities. The study concluded that that a university can teach HIV and AIDS content in different semesters of the academic calendar. It was therefore recommended that HIV and AIDS deserve the political will, recognition and support from designers just like any other subject, move beyond the traditional passive methods and try also video-assisted education models that increase subject's knowledge significantly and that NGOs and HIV and AIDS coordinators, since they offer technical and financial support, should be conversant with the methods used by the lecturers to a lager extent.
\end{abstract}

Keywords: Methods, implementers, HIV, AIDS, programmes

\section{Introduction}

Methods used by implementers are strategies or means which are used to teach and to distribute HIV and AIDS related information or material (Walklin, 2002; Coleman; Jolly and Middlewood, 2003). Programme facilitators during seminars and workshop training as well as lecturers are mandated to use a variety of these methods. Gao et.al, (2008) conducted a study on effectiveness of institutional-based AIDS Education programme among rural students in HIV High epidemic area of China. Gao (2008:184) established that, "the intervention increased subject's knowledge significantly. However, no significant change was observed on respondents' attitudes towards premarital sex." In this case, the literature consulted reveals that methods used (such as lecture method) by implementers, are failing to effect behaviour change as the case should be. On students, Pohan et al (2011:528) advise that, "HIV and AIDS curriculum topics should be offered to the students using participatory learning methods to enhance students' skills in self-management as well as increasing their knowledge develop positive attitudes and behaviour related to HIV prevention." Similar reports have been made in different parts of the world on the importance of participatory methods involving discussions with students (Mohammed, 2006; Gao et. al, 2008).

For instance, information consulted on general universities practices (Coleman, Jolly \& Middlewood, 2003) reveals that, much information is through small group meetings with students. However, critics argue that it is not clear to what extent the universities articulate participatory learning methods. When conducting Peer Education, workshop training by external experts, it may not always be possible in larger groups. HIV positive health promoters often participate in these discussions but large numbers need more manpower and varied methods which cater for all students. Participatory methods for HIV and AIDS mainstreaming should discuss pertinent questions that are formulated by the students, such as rape, gender inequality, homosexuality, gender-based violence and issues related to relationships and sexuality (Gao 
et. al, 2008). It also includes the use of a number of other media including drama and music. Innovation should take the form of designing posters and cards. The interventions, to a large extent, build on interaction with the student population, which plays a very active role. Mukoma, Flisher, Ahmed, Jansen, Mathews, Klepp, and Schaalma (2009) conducted a survey on Process Evaluation of institution-based HIV and AIDS Interventions in South Africa. On implementation strategies (for HIV and AIDS Mainstreaming programme), they established that a few HIV and AIDS trained lecturers used role-plays which they found to be time consuming, small group discussion, which they found to be difficult to implement due to large class sizes. It becomes a problem to keep the groups focused on topic in terms of discipline. The other methods cited include Homework and students" experiences. The researchers, Mukoma et al (2009:46) concluded that, "Young people generally enjoy participatory activities." Coleman, Jolly Middlewood (2003) advocate for methods that validate student experience and encourage active learning. According to Coleman, Jolly and Middlewood (2003:171), "The focus is on learning and learners rather than teachers and teaching."

Literature on teaching and learning in further education under the theme of teaching principles by Walklin (2002:43) claim that at least three different methods of instruction are used in universities namely, "didactic, socratic and facilitative." Didactic materials are instructional materials that assist teaching and learning. The term didactic is also used to describe methods of instruction that are designated to allow the passing of information or facts with little intellectual activity on the part of the students (Walklin, 2002). Socratic involves a series of carefully planned questions that are asked with the intention of leading the students towards the statement of a principle or truth or solution to a problem, using step- by- step questioning. This encourages insight, contemplation, active and creative participation by all students. Facilitative teaching is student-centred rather than lecturer-centred and is designed to encourage a high level of participation, with students accepting a considerable sense of responsibilities for their individual learning outcomes. The lecturer acts as a catalyst or facilitator of the learning environment (Walklin, 2002). The ideas that rose under this section link or relate to this study which also sought to establish the methods used by implementers to teach and to distribute HIV and AIDS related information or material. The researcher contends that student engagement, regarding the methods of delivery cannot be under-estimated nor ignored. The study captures that if an appropriate outcome is to be realised in terms of programme implementation, effective methods/strategies (including class sizes) should be envisaged.

With regards to integration or mainstreaming of HIV and AIDS in the curriculum, cited literature lament that most universities have integrated HIV and AIDS into the curriculum for medical and academic purposes with little focus on the personal risk of HIV and AIDS on students' lives (UNESCO Document, 2007:9; Chitando, 2008). Literature consulted reveals that there are differences between mainstreaming and integration of HIV and AIDS in the curriculum. The two are different and have different outcomes.

\section{Integration of HIV and AIDS in the Curriculum}

Integration of HIV and AIDS in the curriculum entails those subjects that build on existing courses (AAU, 2007). The specific method options available for course developers are: Core course, Foundation Course, Stand Alone Course. To elaborate further, teaching and learning of most of the relevant material is addressed in one main carrier subject (IBEUNESCO, 2006). This approach has generally been found to be less effective than the other approaches (IBE-UNESCO, 2006). The argument is that, HIV and AIDS education has been added to an already overcrowded curriculum (Miedema, 2006), in (IBE-UNESCO, 2006). HIV and AIDS education is often added to the existing syllabus of a particular mandatory subject, but no provisions are made to make sure that HIV and AIDS education is taught or that learning outcomes are assessed in meaningful way, (Miedema, 2006, in IBE-UNESCO, 2006). Another source echoes that, HIV and AIDS education can be integrated into an existing subject to which the epidemic may be relevant, such as civics, religious education, social ethics, social studies, or health education (UNAIDS and WHO, 2006). The advantage of this approach is that the carrier subject lecturers are likely to see the relation between HIV and the other aspects of the subject. These lecturers are also likely to have a greater grasp of the subject and be able to find appropriate examples and issues owing to their experience in teaching the subject. The training of lecturers on how to integrate HIV and AIDS into their subject areas of competence is also likely to be easier, faster, and cheaper than through infusion or creating a separate course (UNAIDS and WHO 2006). It was also established that the very basis of curriculum integration is students' needs on significant issues that affect their lives. Brown in Stern and Kysilka (2008) insist that the primary purpose of engaging students in curriculum integration is to provide them with a genuine democratic education and activities that can yield results to practical solutions. However, Wood (2011:181) laments that, "Currently there is very little integration of HIV and AIDS into curricula at higher education institutions." Curriculum integration occurs in some Higher Education Institutions, but mostly on a limited scale (HEAIDS, 2010). 
The findings from Wood (2011), suggest that the students in universities found the integrated modules to be interesting and offering them new perspectives on the educational consequences of the pandemic. However, on part of the lecturers, there was little evidence of an in-depth understanding of how to practically adapt pedagogical processes and curriculum content to integrate HIV and AIDS meaningfully into their teaching. In particular, there is a wide gap between the idea of a project held by its central planners and the realities of its implementation (Kelly, 2007). In other words, institutions are blamed for concentrating on the implementation plans yet disregarding the impact of their programmes on students. Literature unveils that in the beginning when the epidemic started, Medical/Health centres were blamed for lacking the social solution to treat the problem of infections as they opted for medication of observable problems in most cases. But from then on, some researchers have argued that governments have looked at HIV and AIDS as an economic as well as social issue. For example, one source maintains that despite the need to implement a multi-sectoral response, the response has largely been bio- medically driven by the health sector (ZHD, 2003).

For the purpose of this study, critical pointers have been captured which are relevant to this study. These are guidelines to establish whether HIV and AIDS education is often added to the existing syllabus of a particular mandatory subject or it is being mainstreamed. Also, to establish whether there is any training of lecturers on how to integrate HIV and AIDS into their subject areas of competence. Significant issues that affect the integration of HIV and AIDS into the curriculum, including provisions were also quizzed.

\section{Mainstreaming HIV and AIDS into the Curriculum}

One main outcome of HIV and AIDS policies in a tertiary or higher education institution should be the mainstreaming of HIV and AIDS into the formal and non-formal curricula. HIV and AIDS education needs to be incorporated into the curriculum of all faculties. Students and staff need to be "HIV-aware, HIV-competent and HIV-safe" (Coombe, 2002). HIV and AIDS can be taught as a compulsory subject or topic across all degrees or diploma courses in the institutions. This could entail providing information on basic epidemiological facts about HIV and AIDS, the impact of HIV and AIDS on society, and desirable protective behaviour vis-à-vis HIV and AIDS, such as safer sex practices and life skills. To ensure students take the teaching seriously, compulsory questions should be included in their examinations to assess their competence in understanding the critical issues.

Another option is infusing HIV and AIDS into the curriculum. For example, the Africa University in Zimbabwe and the University of Botswana have taken steps to mainstream HIV and AIDS education into many of their training programmes. Infusion would give students a greater understanding of how to mitigate the impact of HIV and AIDS in their area of expertise such as in Commerce, law and Arts. This will require that students be taught to understand the epidemic and its ramifications on the society including such issues as: what has caused the epidemic to unfold in the way that it has? How has the response of the state helped or hindered the response? What is the role of the private and public sector in addressing HIV and AIDS? How will an effective workplace programme be developed in the sectors in which the students are employed? Tertiary and higher education institutions might also wish to consider integrating HIV and AIDS into non-curricula activities such as sports, or creative arts like drama and music subjects, going to see plays and concerts, and debates. The current study also reviewed and adopted ideas from a sequential logical path which Higher Education Institutions can follow in the Mainstreaming of HIV and AIDS. According to Setswe (2009:1), "Mainstreaming of HIV and AIDS is a process which enables development actors to strengthen the way in which they address the causes and consequence of HIV and AIDS; adapting and improving both their existing work and their work place practices (UNAIDS, World Bank \& UNDP, 2005). In other words, the curriculum content has to be planned and infused into the university subjects as a way of preventing HIV and AIDS. Setswe (2009) proposes a strategic plan for mainstreaming HIV and AIDS in universities. Setswe (2009) advises that mainstreaming of HIV and AIDS is not adding on a few selective additional functions and responsibilities, instead it is reviewing the core business of the university from a different perspective and refocusing it.

\section{Strategic Areas for HIV and AIDS Mainstreaming}

Table 1 below gives a summary of Strategic areas for HIV and AIDS mainstreaming in form. 
Table 1: Strategic areas for HIV and AIDS mainstreaming

\begin{tabular}{l}
$\begin{array}{l}\text { a) HIV structures established and functioning eg. Operational unit for HIV management established headed by senior officials, } \\
\text { university sub-committees put in place. }\end{array}$ \\
$\begin{array}{l}\text { b) Enabling policy in place and mechanisms to ensure that all employees and students in the university are adequately } \\
\text { informed. }\end{array}$ \\
\hline c) HIV and AIDS mainstreamed into all planning and budgeting \\
\hline d) HIV and AIDS mainstreamed into all human resource functions. \\
\hline e) Workplace HIV and AIDS programmes developed, implemented and monitored. \\
\hline f) HIV AIDS mainstreamed into curricular-information and material dissemination. \\
\hline $\begin{array}{l}\text { g) Support, youth peer educators recruited, trained and supported, teaching material amended for different levels and to } \\
\text { conform to outcome based methodologies. }\end{array}$ \\
\hline
\end{tabular}

Source: (UNESCO: 2008)

With reference to Table 1, HIV structures should be established at the university. The HIV structures would include operational unit for HIV management that would be headed by senior officials. In addition, university sub-committees should be put in place as part of the structures. Areas for action are then followed by Guiding Principles of mainstreaming Setswe (2009). To elaborate this point, an enabling HIV and AIDS policy can be in place and mechanisms set to ensure that all employees and students in the universities are adequately informed. Here universities should understand that the mainstreaming of HIV and AIDS impact mitigation activities within university sector plans hence should be a priority. Also, they should ensure that, addressing HIV and AIDS is not an add-on or separate activity but rather an integral part of the university policies, strategies and action (UNESCO, 2008).

According to Table 1, HIV and AIDS should then be mainstreamed into all planning and budgeted for. HIV and AIDS are then mainstreamed into all human resource functions. From another source, literature unveils that steps for internal mainstreaming should include training and capacity building for staff and students about mainstreaming so that they understand the links and are motivated to mainstream (UNAIDS 2005). It includes community research with beneficiaries, modifying development activities in order to minimise negative effects and maximise the positive effects and ensure condom distribution in the university (UNAIDS 2005).It is also recognised internationally that providers of HIV and AIDS programmes should be mindful of professional development when designing Health programmes for universities (Pellert, 2007; Ornstein \& Hankins, 2004). In fact, they urge them to embark on hiring qualified and training of lecturers as both a guide prior to actually conducting the programme (Setswe, 2009).

The study captures that these aspects are relevant in addressing the main research question since it was also the intention of the researcher to investigate whether planning was also done for financial budget, human and material resources by the universities. The researcher is also informed that, when programmes are mainstreamed, they should be supported with teaching material. Similar ideas on mainstreaming were echoed by (UNDP, 2005, UNESCO, 2008). Literature also emphasises on supporting youth peer educators who take part in awareness campaign programmes. UNESCO (2008) has advised that University stakeholders such as the health sector and National AIDS Council should take the lead on all HIV and AIDS activities in the higher education sector.

The critical point to note at this stage is that the current study is guided on assessing how the programmes are implemented (mainstreamed) with reference to: management structures, policy formulation, provision of materials, monitoring and support of peer educators when mainstreaming HIV and AIDS in the curriculum. The issues raised above should not be underestimated. The current study is concerned about time factor if these strategies are to materialise. Research conducted on duration and time span for programme implementation on staff professional development revealed that time factor is a cause for concern. Several authors including Penuel, Fishman, Yamaguchi \& Gallagher (2007) have pointed that a common criticism of professional development activities designed for lecturers is that they are too short and offer limited time. This argument was supported by Brown (2004) who argues that Professional development that is of longer duration and time span is more likely to contain the kinds of learning opportunities necessary for lecturers to mainstream new knowledge into practice.

This section reviewed and adopted ideas from a sequential logical path which Higher Education Institutions can follow in the Mainstreaming of HIV and AIDS. "Mainstreaming of HIV and AIDS is a process which enables development actors to strengthen the way in which they address the causes and consequence of HIV and AIDS; though adapting and improving both their existing work and their work place practices as noted by (UNDP, 2005). In any sector, HIV mainstreaming should result in the epidemic becoming part and parcel of the routine functions and functioning of a sector. 
It should result in the provision of prevention services, and in the mitigating of the impact on the clients of the sector and it is an integral part of the planning, budgeting, implementation, monitoring activities of the sector (UNESCO, 2008). Still on methods used, training is another important area which is an issue in terms of programme delivery and support strategies. From a survey conducted in Zimbabwe, it has also been availed from literature consulted that cluster lecturers received five day training sessions (Rembe, 2006). Three days were devoted to acquiring thorough knowledge on HIV and AIDS awareness, how HIV and AIDS affect teachers as individuals and the impact of HIV and AIDS on communities. The other two days were used to train teachers on using participatory methodology (Rembe 2006).

\section{Methods in Peer Education Programmes}

Peer education is a health promotion and intervention strategy. It refers to unleashing the potential of individuals to transform their lives and those of the members of their communities (Family Health International, 2007). This involves empowering individuals so that they are able to make informed decisions about the challenges they face. It is also about identifying and equipping individuals to influence their peers through positive peer pressure or the modelling of socially acceptable behaviours.

According to (HEAIDS, 2010:4) peer education is:

A process in which trained supervisors assist a group of suitable learners to: educate their peers in a structured manner, informally role model healthy behaviour, recognise youth in need of additional help and refer them for assistance, advocate for resources and services for themselves and their peers.

It is worth noting that peer educators are supposed to be selected, trained and supervised. Suggestions: Rigorous selection, Comprehensive training and retraining, PEs routinely followed-up. Literature shows that main methods in peer education programmes relate to the main functions of Peer Educators (PES) and include information, awareness raising and advocacy for PEs as role models. The general pattern in most Sub-Saharan Universities reveals that intensive activity during Orientation Week for first year students is crucial and constitutes the major activity (Kelly, 2007). After initial orientation, Peer Educators conduct a number of activities. These include: Digital story-telling, as Peer Educators conduct story-telling workshops to allow survivors of gender-based violence, witnesses of abuse, and individuals who have been subjected to HIV and AIDS-related stigma, to write and record first-person narratives about their lives (Family Health International, 2007). The goal of the storytelling circle is to provide these individuals with the support, skills and equipment they need to create original multi-media pieces (using still images, video clips, photos and music) to illustrate the impact these events had on their lives (Family Health International, 2007). In some universities, according to (HEAIDS, 2010), methods used include "Gender-Based Peer Education Project". The aim of this project is to address gender power issues, masculinity issues, issues of sexual consent, sexual and reproductive health, gender-based violence, other STIS, and to look at safer sexual behaviour within a gender context. Awareness raising takes place through a variety of media which includes the use of drama and music. Innovation takes the form of designing posters and cards.

One reason this is not given more attention could be the emphasis on student participation in planning PE activities. Research has shown that PE exists at some of the selected universities in Africa but also limited in time allotment (AAU, 2007). In other words, they need more time for them to function effectively. In the universities where a survey was conducted, results reveal that, peer education mainly consists of activities during the so-called "Orientation Week" at the beginning of term and in follow-up sessions during the semester (HEAIDS, 2010). The survey established also that, Peer educators received annual training to conduct a series of 10 workshops with first year students in the evenings in student residences. The researcher also learns that Peer educators in universities must be provided with opportunities to learn about the HIV and AIDS programmes and how they apply to their work (Deutsch \& Swartz, 2005). The study captures that Peer educators must also be offered opportunities to practice these skills so that they can become competent in helping students to change their behaviour (HEAIDS, 2010). These areas had to be investigated by this study.

\section{Methods in Training and Workshops}

There are several methods used by universities in training and workshops. With reference to curriculum material and support information, it should be noted that there are different methods used by facilitators to implement the programmes (Coombe, 2002). As an illustration, universities employ lecture, exposition and group discussions methods and 
sometimes distribute hand-out material based on their Coping Skills Manual/Module. Besides the training and supplying of qualified and experienced lecturers in universities by MOHTE, support is also needed (World Bank, 2008). From another source, the training manual serves as an important guide intended for use, either as part of training workshop to develop knowledge and skills (MOHCW, 2009). During seminars and workshops, the training is meant for the students and the lecturers as well. At the University of Zambia as an example, the Counselling Centre in conjunction with Counselling and Training Trust conducted a study in 2000. This is a credible source of information that specifically explored the knowledge, attitudes and practices toward HIV and AIDS of students at the University level (AAU, 2007). It involved a sample of 1,240 students. From this survey conducted, literature shows that methods in training and workshops included: group training on HIV and AIDS information, education, and communication. The strategy involved special skills training in peer counselling and education for HIV and AIDS, assertiveness and negotiations for safe sex practice, condoms promotion and use, sustainable social behaviour change. These were found to be effective (AAU, 2007).

With reference to Peer Educators leadership, sometimes university management may use a one on one training method through the counselling department (Deutsch\& Swartz, 2004). However, the same authorities lament that in some universities in South Africa, there are challenges being faced by university management regarding the methods in training and workshops. Deutsch \& Swartz (2004)'s research found that peer educators are often first or second-year students with limited life experience and no training in behaviour change theory or techniques. The cause for concern is that, second year students would be expected to be experts if the training they received in the first year was effective. Furthermore, the researcher reasons and captures that if training and workshops are regularly conducted, as part of staff development, students would be effective on campus' HIV and AIDS Peer awareness campaigns.

\section{Methods in Material Distribution}

Literature reveals that Condom distribution is an integral part of HIV prevention in universities (Altrichter, 2000; UNESCO, 2007). It has been noted that condom dispensers are routinely placed in strategic locations, such as toilets and health care centres (Altrichter. 2000). Procurement of condoms from the Department of Health facilitates universal and uninterrupted condom availability on campuses. The review on who should distribute condoms at the university campus has identified mixed results. For instance, while more studies have reported it as the responsibility of lecturers and cleaning staff, other studies suggest that such responsibility lies in the hands of peer educators (HEAIDS, 2010). At some universities, the cleaning staff is responsible for condom distribution. But, it is usually the responsibility of PEs at the universities of Zambia, Namibia and Zimbabwe (UNESCO, 2007). The students have formed anti-AIDS clubs and actively participated in condom distribution (Family Health International, 2007; AAU, 2007). These may also be kept and distributed by the Janitor in student residences (Family Health International, 2007). From such practices, some authorities contend that behaviour change among the peer educators themselves may be possible (Deutsch \& Swartz, 2005).

Literature has shown that, the numbers of condoms reported to be distributed to students vary from 3 to 26 per student per year in most Sub Saharan Africa universities (Deutsch \& Swartz, 2005). Critics have argued that, although statistics tracing the distribution of condoms are generally kept, it is virtually impossible to ascertain the actual use to which such condoms are put. The likelihood of government-sponsored condoms being put to waste and not to use in a sexual encounter cannot be neglected due to a common lack of trust of the quality of these condoms (Altrichter, 2000). Universities also use door to door service delivery of pamphlets, brochures and T-Shirts (Altrichter. 2000; Dube 2005). On part of NGOs, HIV and AIDS Coordinators and lecturers, research has shown that material can be distributed through the internet and this can be accessed by students on the computers in the university library (Dube 2005). What this study captured is that, the issue of HIV and AIDS methods in material distribution requires concerted efforts to address it using a multi-sectoral approach. It should not be viewed as an individual responsibility, but rather as a collective one. The information was relevant to this study which investigated how programmes were being implemented in universities under study.

\section{Research Methodology}

\subsection{Research Paradigm}

Post-positivism was preferred in this study since it accommodated ideas from both the positivist and interpretivists world views; hence it was a flexible paradigm. Researchers working in the post-positivist framework combine both qualitative and quantitative methods. The idea is to capitalise on real facts, emphasises the importance of multiple measures and 
observations, to use triangulation across these multiple errorful sources to try to get a valid and reliable picture (Trochim, 2006). This enabled the researcher to make use of different data collection instruments so as to come up with the true picture on the methods implementers use in delivering the HIVIAIDS programmes in universities.

\subsection{Research Design}

This study employed the concurrent triangulation design. Concurrent procedures are less time-consuming. Maree, (2007) noted that the concurrent triangulation design can be selected as the design to confirm, cross-validate, or corroborate findings within a single study.

\subsection{Population}

In this study, the population comprised 7 universities, 37200 students, 1135 academic employees.

\subsection{Sample and Sampling Procedures}

Three universities, 30 lecturers from the faculty of Education, 9 lecturers for the focus groups, 24 students, 3 senior health workers and 3 NGO officials formed the sample. The lecturers for quantitative and qualitative data were selected through stratified sampling. The purposive sampling technique was used for the 8 students for each university for focus group discussions, NGO officials and senior health workers as these were rich in information on the area under study.

\subsection{Data Collection Methods}

In this study, data was collected through the use of questionnaires, face to face interviews, focus group discussions, document analysis and observations.

\subsection{Research Instruments}

Nine lecturers, 3 NGO officials and 3 Health officials were interviewed. The aim of an interview is to see the world through the eyes of the participant and they can be a valuable source of rich, descriptive information that will help you to understand the participants' construction of knowledge and social reality on methods implementers use in delivering the HIVIAIDS programmes in universities (Maree, 2007). These observations were also considered to be relevant to this study.

Twenty four students made up the focus group. The researcher noted that the safe environment stimulated them to talk freely as they revealed facts and opinions on the subject. This yielded data that gave insights into the area under study.

In this study, self-administered group questionnaires were employed. Questionnaire is certainly a practical way to collect data and can be used to collect large quantities of data from considerable numbers of people over a relatively short period of time (Leedy \& Ormroad, 2005). In this study, the questionnaire had an advantage of being administered to 30 lecturers in a large geographical area, making it possible to save time and generally, it provided a higher percentage of responses (Cohen, et al., 2000).

Documents with a bearing on methods implementers use in delivering the HIVIAIDS programmes in universities were analysed.

Observations were used in this study. The researcher had to decide on what to observe, being guided by the research questions of the study. Observations enabled researchers to understand the context of the programmes, to see things that might otherwise be unconsciously missed, to discover things that participants might not freely talk about, in interview situations (Cohen, Manion and Morrison, 2007). The advantage of observation was that behaviour was recorded as it occured and as an outsider the observer could see phenomenon about a situation which the people involved took for granted (Moyles, 2002).

\subsection{Data Analysis}

SPSS computer software was used to analyse quantitative data. Qualitative data was grouped into themes for easy analysis. 


\subsection{Measures to ensure Validity/ Reliability and Trustworthiness}

The instruments were designed in such a way that they measured what they are supposed to measure (Maree, 2007) that is, the methods implementers use in delivering the HIV/AIDS programmes in universities. Credibility was achieved through the following procedures: peer debriefing, persistent observation and triangulation (Babbie and Mouton, 2005).

\subsection{Ethical consideration}

In this study, participation was voluntary. Participants were given an opportunity to indicate their willingness to participate in the study by signing an informed consent form provided by the researcher without necessarily providing names. The researcher had to negotiate with gatekeepers so as to get permission to have access to participants at research sites. Names of participating universities as well as lecturers, NGO officials, students, Health officials remained anonymous for they were given pseudo names.

\section{Results and Discussions}

\subsection{Methods used by implementers in delivering the programmes}

\subsubsection{Integrating HIV and AIDS in the curriculum}

The following responses in Table 2 were solicited from the lecturers' questionnaire on Integration of HIV and AIDS in the curriculum.

\begin{tabular}{|l|c|c|c|c|}
\hline $\begin{array}{l}\text { Curriculum Aspect of } \\
\text { HIVIAIDS programme }\end{array}$ & $\begin{array}{c}\text { Responses from } \\
\text { university A lecturers }\end{array}$ & $\begin{array}{c}\text { Responses from } \\
\text { university B lecturers }\end{array}$ & $\begin{array}{c}\text { Responses from } \\
\text { university C lecturers }\end{array}$ & $\begin{array}{c}\text { Percentage of } \\
\text { responses }\end{array}$ \\
\hline Is taught once a year. & 2 & nil & 2 & $4(13 \%)$ \\
\hline Is spread across the year. & 7 & 10 & 6 & $23(77 \%)$ \\
\hline $\begin{array}{l}\text { Is taught as a stand-alone } \\
\text { subject. }\end{array}$ & 2 & 8 & 2 & $12(40 \%)$ \\
\hline $\begin{array}{l}\text { Is taught as part of other } \\
\text { subjects }\end{array}$ & 8 & 2 & 8 & $18(60 \%)$ \\
\hline $\begin{array}{l}\text { Is allocated at least 2 hours } \\
\text { per session }\end{array}$ & 4 & 8 & 3 & $15(50 \%)$ \\
\hline
\end{tabular}

From the overwhelming evidence of the greatest percentage 23(77\%), the study established that the programme was being taught throughout the year at all universities. A very small percentage 4(13\%), indicated that it was being taught once per semester. These findings correlate with what was revealed in the interview discussions with focus groups lecturers under the three universities. Participants were also asked to indicate and describe how HIV and AIDS had been integrated into the University. The majority participants of from universities 1 and 3 18(60\%) indicated that it was being integrated as a part of other subjects while at University 2, 8(80\%) indicated that it is being implemented as a stand-alone subject.

One female lecturer participant in the focus group discussions had this to say:

This examinable HIV and AIDS course is known as "SAY WHAT". Students cannot proceed to the next level if they fail this course.

This study revealed that the time allocated for HIV and AIDS lessons in the curriculum was not adequate. Through document analysis and students interview data, the researcher noted that the block sessions for some universities do not actually cover specifically an HIV and AIDS topic in 2 or 3 hours like other curriculum subjects. In an endeavour to understand further the integration of HIV and AIDS curriculum aspect, it was established that the HIV and AIDS prevention programmes in the curriculum did not sufficiently address the pandemic in all Universities. 11(36\%) had a NO response, 10(33\%) were uncertain while 9(30\%) were in the affirmative. In this case, the researcher concluded that the objectives of the programme being implemented were not commonly shared by the implementers and the consumers. Also, it reflected that a gap of knowledge on the performance of the programme in place existed between the policy implementers and the beneficiaries. The pattern which emerged from the above data showed that the programmes were 
not well managed/ coordinated.

Table 3 below shows methods used by implementers in delivering the programmes;

Table 3: Methods used by implementers in delivering HIV and AIDS Curriculum

\begin{tabular}{|l|c|c|}
\hline $\begin{array}{l}\text { Methods used by lecturers to implement } \\
\text { HIVIAIDS curriculum }\end{array}$ & $\begin{array}{c}\text { Frequency of lecturer } \\
\text { responses }\end{array}$ & $\begin{array}{c}\text { Percentage frequency of lecturer } \\
\text { responses }\end{array}$ \\
\hline Drama/ Role play & 5 & $16 \%$ \\
\hline Lecture method & 20 & $60 \%$ \\
\hline Workshops & 10 & $33 \%$ \\
\hline Group discussions & 14 & $46 \%$ \\
\hline Module method & 6 & $20 \%$ \\
\hline Presentations by students/ Assignments & 7 & 235 \\
\hline Hand outs & 4 & $13 \%$ \\
\hline Assessment tests and exam & 8 & $26 \%$ \\
\hline
\end{tabular}

On methods used by implementers in delivering the programmes, it was established that: Lecture method, group discussions, workshops, assessment methods, presentations by students, drama and role play are the main methods used. On workshops the lecturers noted that:

The frequency of these per semester depends on availability of resources such as time, financial and facilitators. The duration of the workshop is usually one day since large numbers of students are involved. There is caution to avoid disruption of the smooth running of lectures and large numbers of students are expensive to keep in terms of provisions.

However, through triangulation of data, qualitative results from lecturers' focus groups revealed that the distance education university methods differed from the pattern of methods used by other universities. It used the module method, assessment method and group discussions in most cases. The module method was the most convenient method of reaching students who were off campus in various centres.

Data was sought from HIV and AIDS coordinators and NGOs on teaching methods since they played a critical role in University programmes. This information was sought also from students because they are the primary consumers/beneficiaries of the programme. HIV and AIDS coordinator for University 1 indicated that tutorials, group discussions and or lecture method were the major methods used to deliver the content. This data confirm what has been cited or noted by the lecturers. From University 2, NGOs and HIV and AIDS coordinator both confirmed that when teaching, the "SAY WHAT" programme, the university lecturers used lecture method, group discussion, assessment methods as key methods of implementing the programme. However, when probed to elaborate further, both respondents from University 2 bemoaned the sizes of classes compared to the number of lecturers: (Lecturer or Student ratio) which gave no room to individual needs for effecting behaviour change. As a result, monitoring and effecting behaviour change became a challenge.

From students' interview data, it emerged that lecture method and group discussions, assessment methods were dominant methods used by lecturers during programme delivery. This data correlates with what NGOs, HIV and AIDS coordinators and lecturers stated in their responses. The researcher reasons that the larger groups of students being taught through mass lectures methods were not effective for behaviour change. However, such practices showed lack of understanding of educational dynamics pertaining to the implementation of HIV and AIDS prevention programmes. There is need to employ methods which cater for small groups, develop access to these target groups through key members and design services to meet needs of each group. The dominant method in universities was cited as lecture method. Critics of this method argue that it does not give enough room for group work discussions to effect behaviour change in students. Rather, more emphasis is on factual knowledge for assignments and exam purposes.

NGOs and HIV and AIDS Coordinators used Training of peer groups as one of the key methods for implementation. Training may take place with small groups of students within 3 to 4 days on campus. Interview discussions revealed that lecture methods, demonstrations, question and answer, group discussions, debate, drama, role play and videos were used during workshops. Facilitators included in most cases the health centre sister in charge and others invited by the organisers. The peer group students confirmed that they got certificates at the end of training. Furthermore, the HIV and AIDS Coordinators stated that they used counselling services for one on one in their specialist rooms. On the other hand, students Awareness campaign was done using different short term and long term means that are critical for behaviour change. These are: flyers, on-campus door to door campaigns, displays, posters and drama. 
Qualitative data on students' focus group interview also sought data on the learning and teaching methods the youth would prefer most. This study established that they would prefer films while a small proportion of these students cited books, drama, Poems and lecture methods. Through further probing, from the three universities, it emerged that Films, seminars, material distribution, HIV peer campaigns, outreach to the society, Hand-outs, Internet, workshops, and drama would be preferred by university students during the implementation of HIV and AIDS prevention programmes. From this list, films Hand-outs, Internet, CDs and campaign programmes would be preferred most. This view was backed up by responses from both (ffgrp and mfgrp) focus groups. The study also quizzed on measures that had been taken to strengthen the capacity of the implementation of HIV and AIDS prevention programmes. Responses from (University 2) lecturers revealed that "It is mandatory that each student does a module on HIV and AIDS which is examined at the end of the year" Others noted the issuance of free condoms, orientation of new members of staff and designing a policy together with the beneficiaries. Responses from (University 1) lecturers revealed that,"It is now mandatory that each programme has a course on the subject HIV and AIDS." Some stated that there is employment of student advisors who counsel students, workshops and seminars have been run to train trainers (implementer capacity). From university 1, it was unveiled that "There has been provision of health services on campus for students and staff, regular workshops and awareness campaigns through Donor funding." "The university should look at how to expand new students' programme."

\section{Conclusions}

This study established that universities authorities tend to endorse a curriculum change approach which implies a linear view of curriculum change. It was learnt that a university can teach HIV and AIDS content in different semesters of the academic calendar. What emerged in this study was that the programme was taught throughout the year at all universities. Although some lecturers indicated that they were uncertain, the number was fairly insignificant. Since some implementers were not certain of the performance of a programme entrusted to them, the study concluded that the programmes are not well managed/ coordinated.

\section{Recommendations}

The following recommendations were made:

- HIV and AIDS deserve the political will, recognition and support from designers just like any other subject.

- Designers should take cognisance of current realities that exist in different institutions of learning with special attention to implementation challenges in order to act timorously.

- Move beyond the traditional passive methods (lecture and material dissemination) and try also video-assisted education models that increase subject's knowledge significantly.

- NGOs and HIV and AIDS coordinators, since they offer technical and financial support, should be conversant with the methods used by the lecturers to a lager extent.

\section{References}

AAU, (2007). The HIV and AIDS Challenge in African Higher Education Institutions: Responding to HIV and AIDS in African Higher Education Institutions. UNAIDS, 2006 Report on Global Aids Epidemic.

Altrichter, H., \& Elliot, J. (2000). Images of educational change. McGraw-Hill International.

Babbie, E and Mouton, J. (2005). The practice of social research, South African Edition: Oxford University Press.

Brown, G. T. (2004). Teachers' conceptions of assessment: Implications for policy and professional development. Assessment in Education: Principles, Policy \& Practice, 11(3), 301-318.

Chitando,E. (2008). Mainstreaming HIV and AIDS in theological education: Experiences and explorations. Switzerland: WCC Publications,

Cohen, L., Manion, L. and Morrison, K. (2000). Research methods in education.(5th Ed). New York: Routledge Falmer.

Cohen, L., Manion, L., and Morrison, K., (2007). Research methods in education. Padstow: Cornwal.

Coleman, M,, Graham-Folly, M and Middlewood, D. (2003). Managing the curriculum in South African schools, London: Commonwealth Secretariat.

Coombe, C. (2000). Keeping the Education System Healthy: Managing the Impact of HIV and AIDS on the Education in South Africa. Current Isues in Comparative Education, 3(1) December 2000. Retrieved from http:// hiv/aidsclearing house.Unesco.org/even.Php.

Coombe, C. (2002). Keeping the education system healthy: Managing the impact of HIV and AIDS on education in South Africa, Department of Education. 
Swartz, S. (2005). An evangelical response to AIDS. Kretzschmar, Louise and Ntha, Moss. Looking back. Moving Forward: Reflections by South African Evangelicals. Johannesburg: The Evangelical Alliance of South Africa.

Dube, I. (2005). Insights into the diffusion of HIV and AIDS information in Higher Education Institutions in South Africa, October, 37, 315327. Pretoria, Elsevier Ltd

Family Health International (2007).

Gao, M ,Yan Cheng, Chao-Hua Lou, Lisa, M, Mueller, et al (2008) Effectiveness of a School-Based AIDS Education Programme Among Rural Students In HIV High Epidemic Area Of China. Journal of Adolescent Health 42 (2008) 184-191 Shanghai, China.

HEAIDS (2010). HIV and AIDS Prevention. Good practice: strategies for public higher education institutions (HEIs) in South Africa. Pretoria: Higher Education South Africa.

IBE-UNESCO. 2006 Widening the field of inquiry; A cross country study of higher education Institutions' responses to HIV and AIDS.

Kelly, K., et al. (2007). Models for funding and coordinating community-level responses to HIV and AIDS. Thousands Oaks: Sage Publications.

Krueger, R.A. and Casey, M.A. (2009). Focus Groups: A Practical guide for applied research 4th Ed. Thousands Oaks: Sage Publications.

Leedy, P. D., \& Ormrod, J. E. (2005). Practical research. Columbus, OH: Pearson Merrill Prentice Hall.

Maree ,K. (2007). Surveys and the use of Questionnaires (155-171) (Ed).First steps in Research. Pretoria: Van Schaik Publishers.

Mohammed, A.M. (2006). Creating opportunities for Continuing Professional Development of teachers: The National Teachers" Institute experience.Lead Paper presented at the 1st NationalConference of the Faculty of Education, Universityof Abuja held from 17th 21st October 2006: Nigeria.

Ministry Of Health and Child Welfare (2009)

Moyles, J. (2002). Observation as a research tool" London: Paul Chapman Publishing.

Mukoma, W, Flisher, J,Ahmed, N, Jansen, S, Mathews, C,Klepp, K and Schaalma,H. (2009). Process evaluation of a school-based HIV and AIDS interventions in South Africa, June 2009, pp37-47, London: SAGE Publications.

Ornstein. C.A. and Hunkins, P.F. (2004). Curriculum: Foundations, principles and issues.(4th Ed) Boston: Pearson Education Inc.

Pellert, A. (2007). Human Resource Management at Universities.and Development in Central, Southern and Eastern Europe, 104.

Penuel, W. R., Fishman, B.J., Yamaguchi, R. and Gallagher, L.P. (2007). What Makes Professional Development Effective? Strategies that Foster Curriculum Implementation.American Educational Research Journal,4 (4), 921-958.

Pohan, M. N, Hinduan, Z. R et al (2011). HIV-AIDS Prevention through a Life-Skills School Based Programme. WCES -Procedia Social and Behavioural Sciences,15(2011) 526-530, 1872-0428 published by Elsevier Ltd.

Rembe, S, (2006). An Assessment of the Policies and Programmes of Zimbabwe in Addressing the HIV and AIDS Epidemic in the Education Sector.

Rogan, J. M. and Grayson, D. J. (2003).Towards a Theory of Curriculum Implementation with Particular Reference to Science Education in Developing Countries.International Journal of Curriculum Studies (In Press).Retrieved from URL.http://dx.dorf. org/10.1080/0950069010145819.

Setswe, K.G. (2009). HIV Prevention: Where is the evidence of intervention?www.slideshare.net/Nicopaul/01-sets.

Stern, B.S. and Kysilka,M.C. (2008). Contemporary readings in curriculum. London: Heinemann Educational Books.

Trochim, W. M. K. (2006). The research methods knowledge base.www.socialreseachmethods.net/kb/contents.php.

UNAIDS (2006). Report on the Global AIDS Epidemic. New York: UNAIDS.

UNDP (2005).Human Development Report. New York, UNDP.

UNESCO. (2008). Higher and tertiary education sector responses to HIV and AIDS in Zimbabwe, DFID, Harare: Zimbabwe, UNESCO.

Walklin, L. (2002). Teaching and learning in further and adult education. Nelson: Thornes.

WHO. (2006) Report on Global AIDS epidemic. Geneva: WHO.

Wood, (2011).A Guide to HIV and AIDS Mainstreaming. Retrieved from www.ilo.org/../wcms.

World Bank Economic Review, (2008) on HIV pandemic, medical brain drain, and economic development in Sub-Saharan Africa. Washington DC.

Zimbabwe Human Development Report (2003). Re-Directing our Responses to HIV and AIDS-Institute of Development StudiesUniversity of Zimbabwe-Harare: GCZ 